\title{
Quantile regression analysis of language and interpregnancy interval in Quebec, Canada
}

\author{
Nathalie Auger, MD, FRCPC (1,2); Lucien Lemieux, MSc (3); Marianne Bilodeau-Bertrand, MSc (1,2); \\ Amadou Diogo Barry, MSc (4); André Costopoulos, PhD (5)
}

This original quantitative research article has been peer reviewed.

Tweet this article

\begin{abstract}
Introduction: Short and long interpregnancy intervals are associated with adverse perinatal outcomes such as miscarriage and preterm delivery, but cultural differences in interpregnancy intervals are understudied. Identifying cultural inequality in interpregnancy intervals is necessary to improve maternal-child outcomes. We assessed interpregnancy intervals for Anglophones and Francophones in Quebec.

Methods: We obtained birth records for all infants born in Quebec, 1989-2011. We identified 571461 women with at least two births, and determined the interpregnancy interval. We defined short interpregnancy intervals ( $<18$ months) as the $20^{\text {th }}$ percentile of the distribution, and long intervals ( $\geq 60$ months) as the $80^{\text {th }}$ percentile. Using quantile regression, we evaluated the association of language with short and long intervals, adjusted for maternal characteristics. We assessed differences over time and by maternal age for disadvantaged groups defined as no high school diploma, rural residence, and material deprivation.
\end{abstract}

Results: In adjusted regression models, Anglophones who had no high school diploma had intervals that were 1.0 month $(95 \% \mathrm{CI}$ : -1.5 to -0.4$)$ shorter than Francophones at the $20^{\text {th }}$ percentile of the distribution, and 1.9 months $(-0.5$ to 4.3$)$ longer at the $80^{\text {th }}$ percentile. Results were similar for Anglophones in rural and materially deprived areas. The trends persisted over time, but were stronger for women $<30$ years. There were no differences between advantaged Anglophones and Francophones.

Conclusion: Disadvantaged Anglophones are more likely to have short and long interpregnancy intervals relative to Francophones in Quebec. Public health interventions to improve perinatal health should target suboptimal intervals among disadvantaged Anglophones.

Keywords: birth intervals, cultural deprivation, language, socioeconomic factors

\section{Introduction}

A growing number of studies report ethnocultural differences in maternal-child health indicators, including preterm birth, delayed fetal growth and stillbirth. ${ }^{1-3}$ However, ethnic or cultural differences in interpregnancy intervals are rarely studied. In the United States, ethnic minorities have interpregnancy intervals that are disproportionately more extreme on both ends of the distribution. Black women have a higher risk of short ( $<18$ months) and long ( $\geq 60$ months) interpregnancy intervals compared with majority White women, and Hispanic women tend to have longer intervals. ${ }^{4-7}$ Short and long interpregnancy intervals are associated with miscarriage, premature rupture of membranes, preeclampsia, maternal cardiovascular disease and mortality. ${ }^{8-11}$ Suboptimal intervals increase the risk of preterm delivery, small-for-gestational-age birth, congenital anomalies, autism disorder,
Highlights

- We investigated differences in interpregnancy intervals between the Anglophone minority and Francophone majority in Quebec, Canada.

- Disadvantaged Anglophones had more suboptimal intervals than Francophones.

- Very short and long interpregnancy intervals were both more common in disadvantaged Anglophones.

- The trends persisted over time, and were stronger for young women.

- There were no differences between advantaged Anglophones and Francophones.

and fetal and infant mortality., ${ }^{9,12}$ It is thought that short interpregnancy intervals do not give women sufficient time to recover from the physical stress of the previous pregnancy, including nutritional depletion..$^{8,11,14}$ By contrast, long interpregnancy intervals do not benefit from adaptions in the genital and cardiovascular systems that recede naturally with time. It is thought that the physiological capacities of women become comparable to those of the first pregnancy, where the risk of diverse maternal-child outcomes is higher. ${ }^{14}$ These effects are believed to be independent of maternal age. ${ }^{8,11,14}$ Better documentation of ethnocultural differences in interpregnancy intervals is needed, since attempts to optimize interpregnancy intervals may improve maternal and perinatal outcomes.

Our objective was to determine if differences in interpregnancy intervals were present between Anglophones and Francophones 
in the province of Quebec, Canada. French is the official language in Quebec, where most of the population is Francophone (79.1\% in 2016) and the minority is Anglophone (9.7\%). ${ }^{15}$ In Quebec, language is associated with cultural norms and access to health care, and is frequently used to measure health differences. ${ }^{16}$ In recent decades, Anglophone socioeconomic status has decreased due to higher unemployment rates and larger proportions living below the low income cut-off compared with Francophones. ${ }^{17}$ Several studies indicate that Anglophones, particularly socioeconomically disadvantaged Anglophones, have increasing rates of stillbirth, preterm birth and small-forgestational-age birth. ${ }^{18,19}$ We investigated the possibility that lingo-cultural differences in interpregnancy intervals were present in Quebec, and assessed trends over time and socioeconomic status. Our hypothesis was that socioeconomically disadvantaged Anglophones are presently at greater risk of suboptimal interpregnancy intervals compared with Francophones.

\section{Methods}

\section{Data}

We obtained live birth and stillbirth files from the Ministry of Health and Social Services for all infants to women who gave birth in Quebec, Canada, 1989-2011.20 The data covered the entire province, and contained maternal characteristics such as language and parity as well as information on the prior delivery. We selected women who had at least two births and focussed the analysis on the interpregnancy interval between the first and second child, as women in Quebec rarely have a third child. We excluded multiple births to rule out the contribution of pregnancy-specific disorders not found in singleton births. There were in total 622812 women who delivered at least two times and had information on language and the timing of the first and second birth.

\section{Language}

To determine the maternal language, we used the language spoken at home which was self-reported on birth certificates and reflects the language used by both parents in the home setting. We considered mothers who reported English with or without another non-French language as Anglophone, following previous research. ${ }^{17-19,21}$ We considered mothers who reported
French with or without another non-English language as Francophone. Due to small numbers, we excluded 10004 bilingual French-English women, as these were too few to analyze. Similarly, we excluded 41347 women with other languages, a heterogeneous group that comprised a wide range of languages which was difficult to interpret. The final sample comprised 571461 Anglophone and Francophone women (Figure 1). For simplicity, we used the terms language and language spoken at home interchangeably hereafter to describe the results.

\section{Interpregnancy interval}

The interpregnancy interval was defined as the time between the first delivery and conception of the second pregnancy. ${ }^{4-7,9,22,23}$ The World Health Organization encourages a minimum interval of 24 months between pregnancies, ${ }^{9}$ following evidence that intervals shorter than 18 months, or longer than 60 months, increase the risk of adverse maternal and perinatal outcomes. ${ }^{8-13}$ To calculate the interpregnancy interval, we subtracted the date of delivery of the first-born infant from the conception date of the second-born infant. We estimated the conception date by subtracting the gestational age from the delivery date, with a two-week correction for the average time of ovulation. We expressed the interpregnancy interval as a continuous variable in months, and for descriptive statistics categorized the interval as short (less than 18 months), optimal (18 to 59 months), or long (60 months or more) following previous literature. ${ }^{4,5,7,9,22}$

\section{Socioeconomic status}

We selected three markers of socioeconomic status, including education (no high school diploma, high school diploma/postsecondary training, university, unknown), place of residence (urban, rural, unknown), and material area deprivation quintile based on a composite score of census data on neighbourhood income, employment and education (low, low-middle, middle, middle-high, high deprivation, unknown). ${ }^{24}$ Education and place of residence were measured at an individual-level, while material deprivation was measured at an area level based on the 1991, 1996, 2001 and 2006 Censuses. We selected these indicators based on current literature of socioeconomic status. Education is a wellestablished marker of socioeconomic status shown to be associated with interpregnancy intervals. ${ }^{4-7,22}$ Rurality is a marker of low socioeconomic status also associated with reproductive health, including short interpregnancy intervals. ${ }^{23,25}$ Material deprivation is an indicator of area socioeconomic status frequently used to investigate perinatal health differences..$^{21,24}$

\section{Covariates}

We accounted for additional covariates possibly related to the interpregnancy
FIGURE 1

Selection of study population

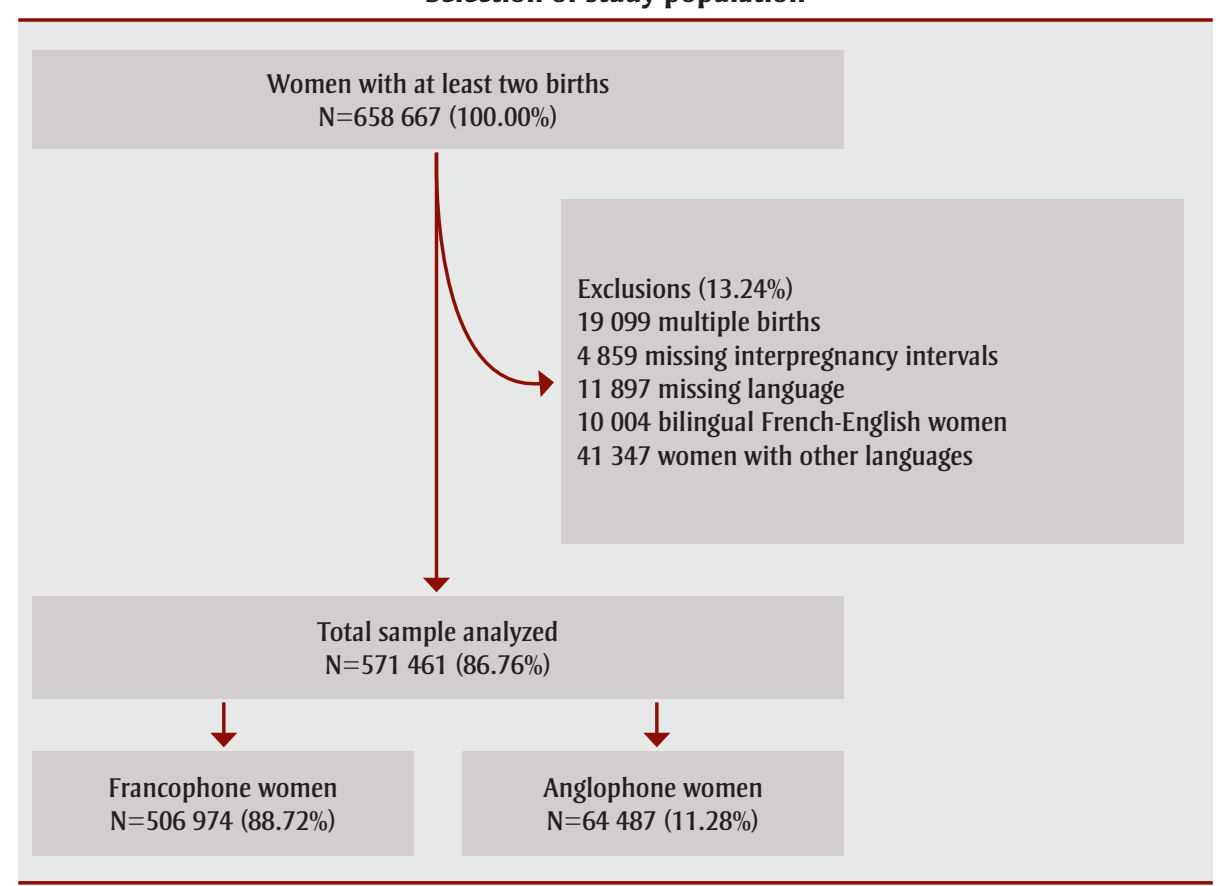


interval, including maternal immigrant status (Canadian-born, foreign-born, unknown) and time period at second delivery (19891999, 2000-2011). Several studies report an association between foreign place of birth and interpregnancy intervals. ${ }^{6,7,22} \mathrm{We}$ included periods to evaluate trends over time, and limited the analysis to two time periods to make sure there were enough women in each period to enable comparisons. We did not adjust for maternal age in the primary analysis, as women who are older at their first pregnancy cannot have long interpregnancy intervals for physiological reasons. Adjustment for maternal age may cause over-adjustment bias in regression models because there are no older women with long interpregnancy intervals. ${ }^{26}$

\section{Data analysis}

We computed the proportion of Anglophone and Francophone women with short (less than 18 months), optimal (18 to 59 months), and long (60 months or more) interpregnancy intervals, and plotted the distribution for each language group according to socioeconomic characteristics. In regression models, we analyzed the interpregnancy interval as a continuous variable. Linear regression is the traditional method used for continuous outcomes. Linear regression estimates the mean difference in interpregnancy intervals between Anglophones and Francophones, but provides no estimate of the difference at the tails of the distribution, ${ }^{27}$ which is a disadvantage since very low and very high intervals are problematic for maternal-infant health, not mean intervals.

We instead used quantile regression, a method that overcomes the limitations of linear regression by analyzing the entire distribution of the interpregnancy interval. Quantile regression divides the distribution of the interpregnancy interval in quantiles of equal proportion. ${ }^{28}$ The relationship with language is modelled at each quantile of the interpregnancy interval. ${ }^{27}$ Thus, quantile regression can assess the association of language with short interpregnancy intervals, as well as with long interpregnancy intervals.

We used quantile regression models with the interpregnancy interval divided in 20 equal quantiles. We considered intervals at the $20^{\text {th }}$ percentile of the distribution as short, and intervals at the $80^{\text {th }}$ percentile as long, because these cut-off points approached the $<18$ months and $\geq 60$ months used in traditional analyses. ${ }^{4,5,7,9,22}$ For both short and long intervals, we obtained the absolute difference in the interpregnancy interval between Anglophones and Francophones in months. We computed 95\% CIs for all estimates, and adjusted for maternal education, rural residence, material deprivation, immigrant status, and time period at second delivery. We tested the interaction of language with socioeconomic characteristics, including maternal education, rural residence, and material deprivation. We assessed trends over time by comparing the association between language and interpregnancy intervals in 1989-1999 with the association in 2000-2011. Because maternal age may modify the associations, we ran regression models with the data stratified by age at first birth $(<30$ vs. $\geq 30$ years).

\section{Sensitivity analysis}

We performed a range of sensitivity analyses. We estimated the association of language with interpregnancy intervals between the second and third birth for 210631 women, and between the third and fourth birth for 60972 women, to determine if linguistic differences persisted over the reproductive course of women. We examined models for Canadianborn and foreign-born mothers separately, to make sure that linguistic differences were not due to immigration. We examined the impact of excluding women who had stillbirth at first pregnancy, using the mother tongue of each parent instead of language spoken at home, and adjusting for maternal age. Finally, we assessed associations after excluding women from Aboriginal areas, since fertility is higher in these regions.

We performed the analysis in SAS version 9.3 (SAS Institute Inc., Cary, NC, USA) We obtained an ethics waiver from the institutional review board of the University of Montréal Hospital Centre, as the study abided by ethical requirements for research on people in Canada.

\section{Results}

In this study, there were 506974 Francophone and 64487 Anglophone women (Table 1). $11.3 \%$ (95\% CI: $11.2-11.4)$ of women were Anglophone. This proportion was slightly lower in women with interpregnancy intervals shorter than 18 months (10.6\%; 95\% CI: 10.5-10.8) and higher in women with intervals of 60 months or more $(12.4 \%$; $95 \% \mathrm{CI}$ : 12.2-12.7). Interpregnancy intervals were generally longer for Anglophones than Francophones. Anglophones had a lower proportion of interpregnancy intervals shorter than 18 months (31.15\% (20089/ $64487)$ vs. $33.35 \%(169068 / 506974)$ for Francophones, $p<.001$ ), and a greater proportion of intervals longer than 60 months or more (14.67\% (9458/64487) vs. $13.14 \%(66599 / 506974)$ for Francophones, $p<.001)$. Anglophones who had no high school diploma, lived in rural areas, or were materially deprived had a higher proportion of very short and long interpregnancy intervals than Francophones (Figure 2). The distribution of interpregnancy intervals was similar for Francophones and Anglophones who had university diplomas, lived in urban areas, or had low material deprivation.

Quantile regression models adjusted for socioeconomic characteristics suggested that there was a linguistic difference in long $\left(80^{\text {th }}\right.$ percentile $)$ but not short $\left(20^{\text {th }}\right.$ percentile $)$ interpregnancy intervals (Figure 3 ). At the $80^{\text {th }}$ percentile, Anglophones had intervals that were 0.8 months longer than Francophones $(95 \%$ CI: $0.4-1.3)$. Interaction terms suggested that differences at the $80^{\text {th }}$ percentile were greater for Anglophones who lived in rural areas $(p<.001)$, or were materially deprived $(p<.001)$. Although there was no difference at the $20^{\text {th }}$ percentile between Anglophones and Francophones overall, interaction terms with socioeconomic characteristics suggested that intervals were shorter for Anglophones who had no high school diploma $(p<.001)$, lived in rural areas $(p<.001)$, or were materially deprived ( $p=.04)$.

\section{Short interpregnancy intervals}

When we examined each socioeconomic group separately, results confirmed that disadvantaged Anglophones had shorter interpregnancy intervals than Francophones at the $20^{\text {th }}$ percentile of the distribution (Figure 4). Anglophones with no high school diploma had intervals that were 1.0 months shorter than Francophones (95\% CI: -1.5 to - 0.4), and Anglophones in rural areas had intervals that were 0.7 months shorter $(-1.0$ to -0.3$)$. However, intervals of materially deprived Anglophones were not statistically different 
TABLE 1

Distribution of interpregnancy intervals for Francophones and Anglophones according to maternal characteristics, 1989-2011, Quebec

\begin{tabular}{|c|c|c|c|c|c|c|c|c|}
\hline & \multirow{2}{*}{$\begin{array}{l}\text { Total no. } \\
\text { Francophone } \\
\text { births }\end{array}$} & \multicolumn{3}{|c|}{$\begin{array}{l}\text { Francophone } \\
\text { interpregnancy interval }\end{array}$} & \multirow{2}{*}{$\begin{array}{l}\text { Total no. } \\
\text { Anglophone } \\
\text { births }\end{array}$} & \multicolumn{3}{|c|}{$\begin{array}{l}\text { Anglophone } \\
\text { interpregnancy interval }\end{array}$} \\
\hline & & $\begin{array}{c}<18 \text { months } \\
\mathrm{N}(\%)\end{array}$ & $\begin{array}{c}\text { 18-59 months } \\
\text { N (\%) }\end{array}$ & $\begin{array}{l}\geq 60 \text { months } \\
\mathrm{N}(\%)\end{array}$ & & $\begin{array}{c}<18 \text { months } \\
\mathrm{N}(\%)\end{array}$ & $\begin{array}{c}\text { 18-59 months } \\
\mathrm{N}(\%)\end{array}$ & $\begin{array}{c}\geq 60 \text { months } \\
\mathrm{N}(\%)\end{array}$ \\
\hline \multicolumn{9}{|l|}{ Education } \\
\hline $\begin{array}{l}\text { No high school } \\
\text { diploma }\end{array}$ & 50219 & 15777 (31.4) & $24635(49.1)$ & 9807 (19.5) & 4673 & $1521(32.5)$ & $2166(46.4)$ & $986(21.1)$ \\
\hline $\begin{array}{l}\text { High school } \\
\text { diploma }\end{array}$ & 294582 & 94821 (32.2) & $157661(53.5)$ & $42100(14.3)$ & 34183 & $10143(29.7)$ & $18276(53.5)$ & $5764(16.9)$ \\
\hline University & 141913 & 52095 (36.7) & $78124(55.1)$ & $11694(8.2)$ & 21651 & $7250(33.5)$ & 12427 (57.4) & $1974(9.1)$ \\
\hline \multicolumn{9}{|l|}{ Residence } \\
\hline Urban & 386250 & 126916 (32.9) & $207695(53.8)$ & 51639 (13.4) & 58875 & $18145(30.8)$ & $32169(54.6)$ & $8561(14.5)$ \\
\hline Rural & 116957 & 40758 (34.8) & $61671(52.7)$ & $14528(12.4)$ & 5243 & $1822(34.8)$ & $2575(49.1)$ & $846(16.1)$ \\
\hline \multicolumn{9}{|c|}{ Material area deprivation } \\
\hline Low & 89948 & 30738 (34.2) & $49539(55.1)$ & 9671 (10.8) & 20086 & 6575 (32.7) & $11335(56.4)$ & $2176(10.8)$ \\
\hline Low-middle & 104191 & $34437(33.1)$ & $56859(54.6)$ & 12895 (12.4) & 12385 & $3748(30.3)$ & $6897(55.7)$ & $1740(14.0)$ \\
\hline Middle & 103812 & 34480 (33.2) & $55638(53.6)$ & $13694(13.2)$ & 9604 & $2888(30.1)$ & $5156(53.7)$ & $1560(16.2)$ \\
\hline Middle-high & 100086 & 33508 (33.5) & $52592(52.5)$ & $13986(14.0)$ & 9390 & $2886(30.7)$ & $4914(52.3)$ & 1590 (16.9) \\
\hline High & 93042 & 30474 (32.8) & $48356(52.0)$ & $14212(15.3)$ & 10695 & $3269(30.6)$ & $5420(50.7)$ & 2006 (18.8) \\
\hline \multicolumn{9}{|c|}{ Immigrant status } \\
\hline Canadian-born & 465011 & $157116(33.8)$ & $249058(53.6)$ & $58837(12.7)$ & 43028 & $13819(32.1)$ & $23941(55.6)$ & $5268(12.2)$ \\
\hline Foreign-born & 37448 & $10515(28.1)$ & $19860(53.0)$ & 7073 (18.9) & 19567 & $5683(29.0)$ & $10030(51.3)$ & 3854 (19.7) \\
\hline \multicolumn{9}{|c|}{ Time period at second delivery } \\
\hline 1989-1999 & 255492 & 85854 (33.6) & $136808(53.5)$ & 32830 (12.8) & 30604 & $9783(32.0)$ & $16624(54.3)$ & 4197 (13.7) \\
\hline $2000-2011$ & 251482 & 83214 (33.1) & 134499 (53.5) & 33769 (13.4) & 33883 & 10306 (30.4) & $18316(54.1)$ & 5261 (15.5) \\
\hline Total & 506974 & 169068 (33.3) & 271307 (53.5) & 66599 (13.1) & 64487 & 20089 (31.2) & 34940 (54.2) & 9458 (14.7) \\
\hline
\end{tabular}

a Percentages are for row totals (not column totals) for Francophones and Anglophones separately.

relative to Francophones $(0.2$ months shorter; $95 \%$ CI: -0.6 to 0.1 ). Anglophones who had university diplomas, lived in urban areas, or had low material deprivation had interpregnancy intervals that were similar to Francophones.

\section{Long interpregnancy intervals}

In contrast, disadvantaged Anglophones had longer interpregnancy intervals at the $80^{\text {th }}$ percentile of the distribution compared with Francophones (Figure 4). Anglophones in rural areas had intervals that were 5.0 months longer than Francophones (95\% CI: 3.5 to 6.5 ), and materially deprived Anglophones had intervals that were 2.7 months longer (1.4 to 4.0 ). Anglophones with no high school diploma had intervals that were 1.9 months longer than Francophones, although the difference was not statistically significant ( $95 \%$ CI: -0.5 to 4.3 ). In contrast, Anglophones who had university diplomas or who lived in urban areas had interpregnancy intervals that were similar to Francophones, and
Anglophones with low material deprivation had intervals that were 1.4 months shorter (95\% CI: -2.1 to -0.7$)$.

When we examined temporal trends over time, the difference between socioeconomically disadvantaged Anglophones and Francophones did not change over time. Differences between socioeconomically disadvantaged Anglophones and Francophones were, however, more prominent for women < 30 years compared with women $\geq 30$ years (Figure 5). At the $20^{\text {th }}$ percentile, Anglophones < 30 years with no high school diploma had intervals that were 0.9 months shorter than Francophones ( $95 \%$ CI: -1.5 to -0.3 ), and those in rural areas had intervals that were 0.7 months shorter $(-1.1$ to -0.3$)$. At the $80^{\text {th }}$ percentile, Anglophones $<30$ years with no high school diploma had intervals that were 2.8 months longer than Francophones (95\% CI: 0.2 to 5.3), those in rural areas had intervals that were 6.4 months longer (4.7 to 8.1), and those in materially deprived areas had intervals that were 3.3 months longer (1.8 to 4.7 ). In contrast, disadvantaged Anglophones $\geq 30$ years had interpregnancy intervals that were similar to Francophones.

In sensitivity analyses, linguistic differences in intervals between the second and third birth were similar to those between the first and second birth, however there was no difference in intervals between the third and fourth birth. Results were similar when data were stratified by maternal immigrant status, after excluding women with stillbirth at first pregnancy, and when we used the maternal or partner mother tongue as the exposure. Adjusting for maternal age had little impact on short intervals, and restricting to young women had no impact on long intervals. Excluding 2923 women from Aboriginal areas did not change the results.

\section{Discussion}

In this study, we found differences in short and long interpregnancy intervals 
FIGURE 2

Distribution of interpregnancy intervals for Francophones and Anglophones, 1989-2011, Quebec
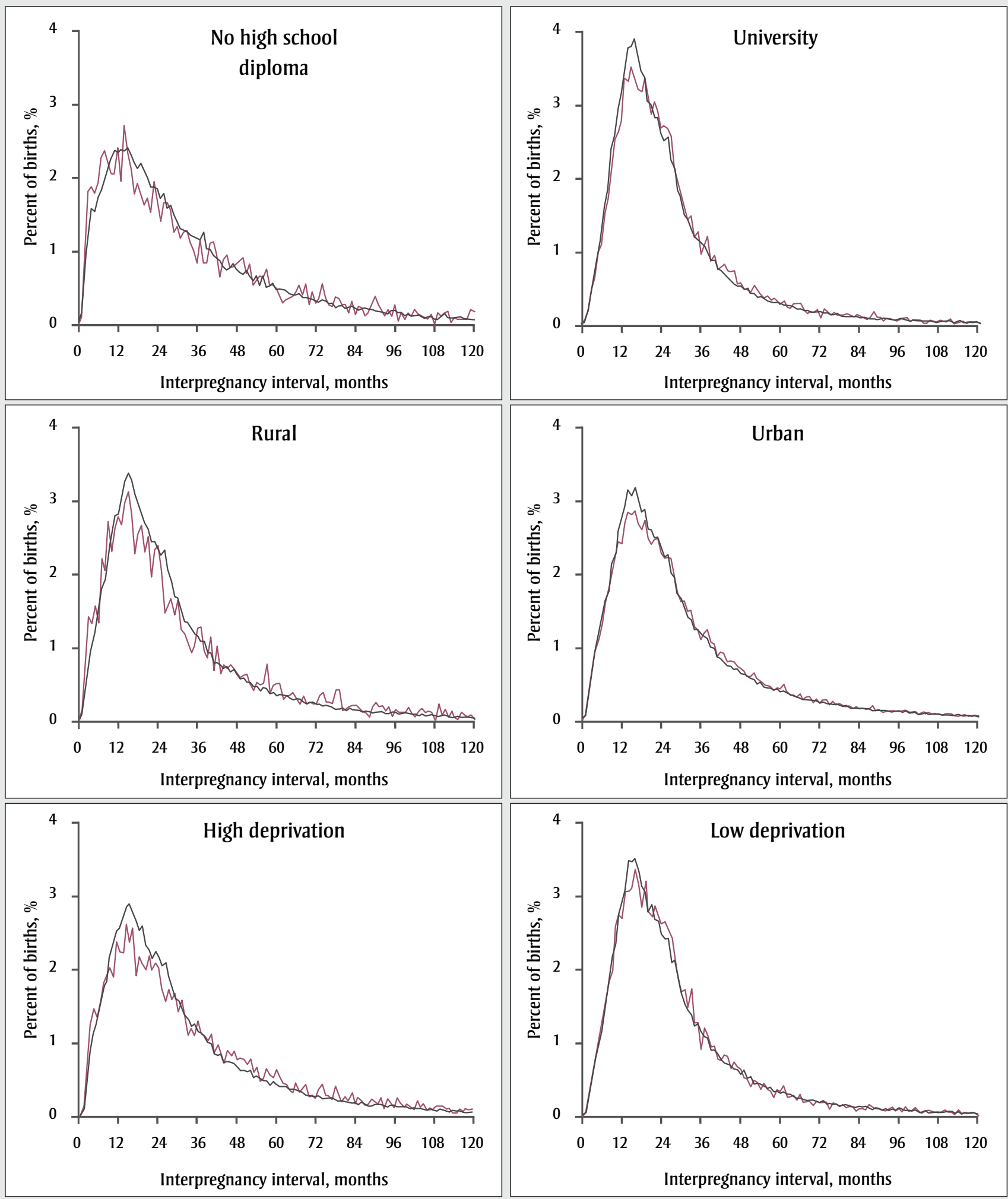

- Francophone $\quad$ Anglophone 
FIGURE 3

Difference in interpregnancy intervals between Anglophones and Francophones, 1989-2011, Quebec ${ }^{\mathrm{a}}$

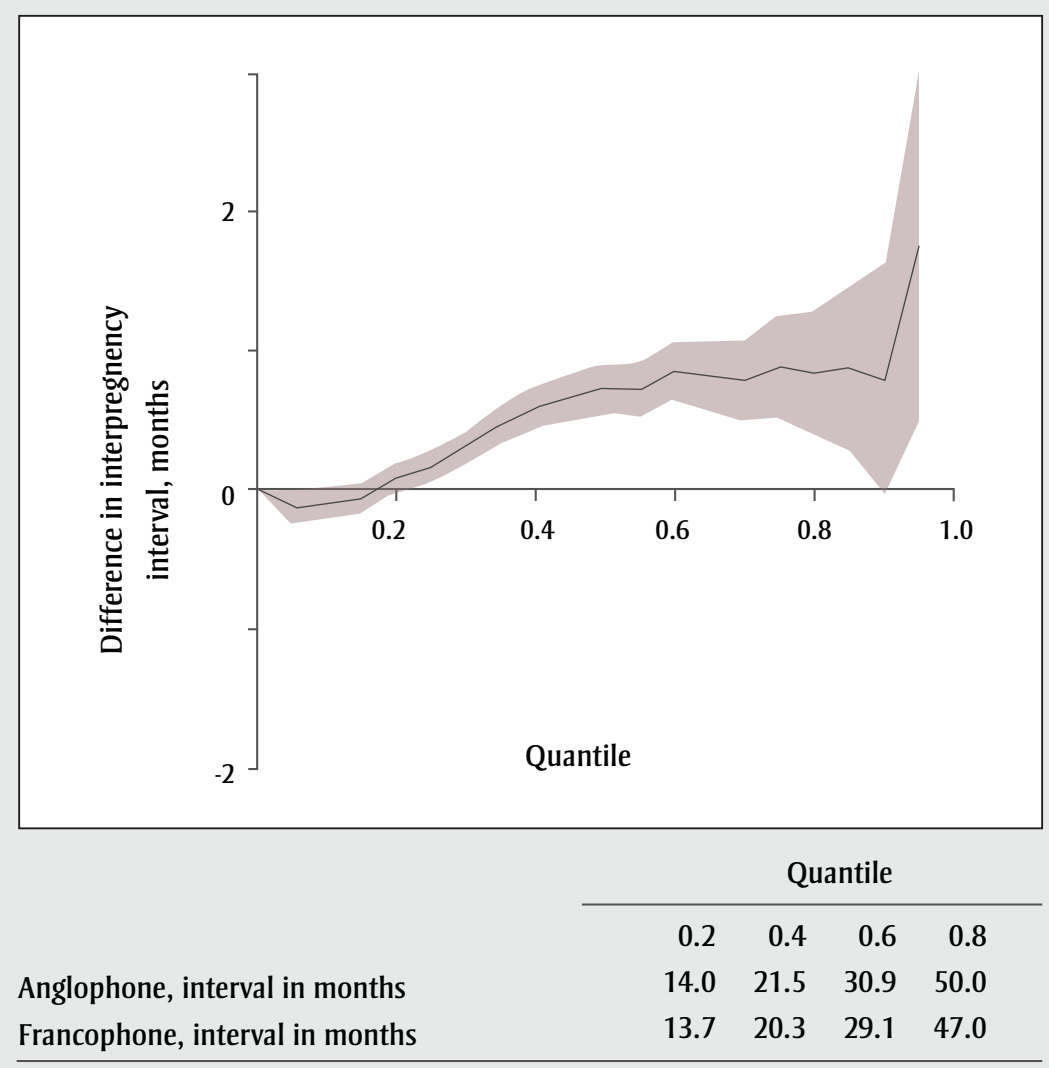

Difference in interpregnancy interval for Anglophones minus Francophones in months (bold line) and 95\% $\mathrm{Cl}$ (grey shade), adjusted for maternal education, rural residence, material area deprivation, immigrant status and period. The $x$-axis indicates the interpregnancy interval quantile, with 0.2 equivalent to short intervals and 0.8 long intervals. Positive values on the $y$-axis indicate that Anglophones have greater intervals than Francophones, and negative values that Francophones have greater intervals than Anglophones.

between Anglophones and Francophones of Quebec. Socioeconomically disadvantaged Anglophones had intervals that were less favourable than Francophones for both short and long intervals. At short intervals, Anglophones with no high school diploma, who lived in rural areas, or were materially deprived had interpregnancy intervals that were systematically shorter than Francophones. At long intervals, Anglophones with no high school diploma, who lived in rural areas, or were materially deprived had interpregnancy intervals that were systematically longer than Francophones. The differences persisted over time, and were stronger for younger women. In contrast there was no difference between socioeconomically advantaged Anglophones and Francophones. These findings add to the growing evidence that socioeconomically disadvantaged
Anglophones may be a vulnerable population in Quebec, and are concerning as Anglophones have higher fertility, ${ }^{21}$ and suboptimal interpregnancy intervals are associated with a wide range of adverse maternal and perinatal outcomes.

Few studies have attempted to measure cultural differences in interpregnancy intervals. ${ }^{4-7}$ These studies however do not investigate the entire distribution of interpregnancy intervals, and usually analyze the interval as a binary outcome. While the trends align with the results in our study, where minority Anglophones also had unfavourable interpregnancy intervals, it is difficult to know if the results are generalizable to minorities elsewhere.

Moreover, there are limited data on how lingo-cultural differences in interpregnancy intervals vary according to socioeconomic status. In some research, socioeconomically disadvantaged women have unfavourable interpregnancy intervals compared with advantaged women. Unemployment, low income, and rural residence are all associated with a higher risk of short interpregnancy intervals. ${ }^{6,23}$ Similarly, women with less education have a higher risk of long interpregnancy intervals compared with highly educated women. ${ }^{6,7}$ However, studies have not tested the possibility of interaction between ethnicity and socioeconomic status. Our results in fact suggest a strong interaction effect, as most of the difference between Anglophones and Francophones of Quebec was limited to disadvantaged women. There was no difference in interpregnancy intervals between advantaged Anglophones and Francophones. Breastfeeding may also affect interpregnancy intervals by delaying menstruation and the next pregnancy. ${ }^{9}$ Breastfeeding initiation and duration differs according to ethnicity, and high education tends to be associated with longer duration of breastfeeding. ${ }^{29}$

Family planning may also differ between linguistic and cultural subgroups. Some women may time their second pregnancies based on culture, age, career, or future income. For example, employed women, or women who are in school may choose to delay pregnancy. ${ }^{4}$ However, researchers have shown that short interpregnancy intervals are frequently unplanned, ${ }^{5}$ particularly for disadvantaged women, ${ }^{23}$ while long intervals can be markers of fertility problems or change of partner. ${ }^{30}$ Indeed, we found that disadvantaged Anglophones who were young were more likely to have very short or long intervals compared with Francophones, suggesting that effects of language are more prominent in young mothers. Family planning may be influenced by health care services, and we cannot exclude the possibility of language barriers in access to information on reproductive health. Disadvantaged Anglophones may be more affected, and have fewer opportunities to receive appropriate advice on contraception and optimal timing of a second pregnancy. French is the official language in Quebec and it is generally easier to receive Francophone health services in many parts of the province, especially in rural areas. ${ }^{16}$

To our knowledge, temporal trends in interpregnancy intervals between ethnic, 
FIGURE 4
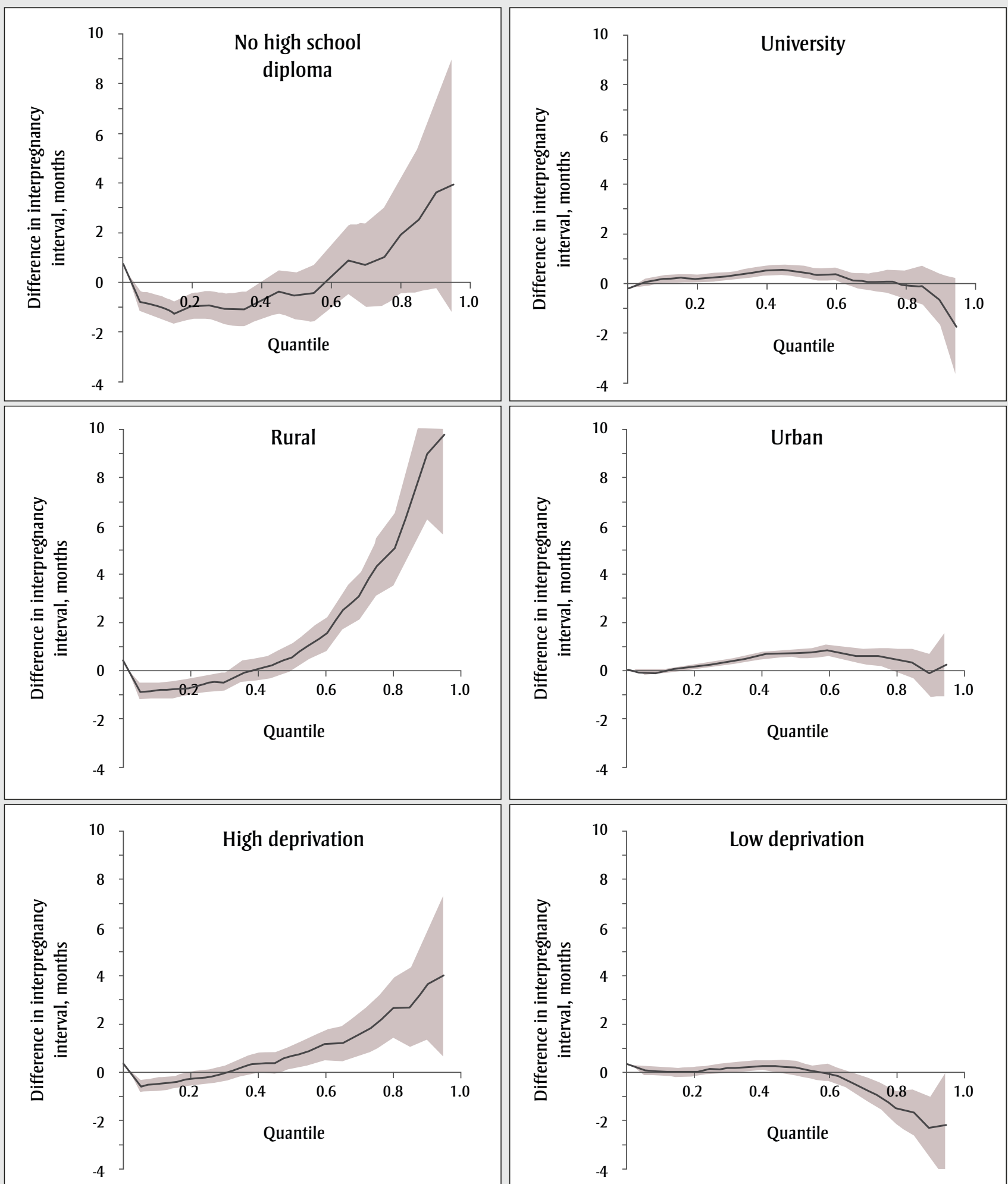

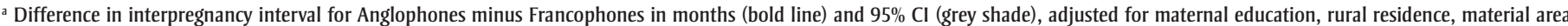

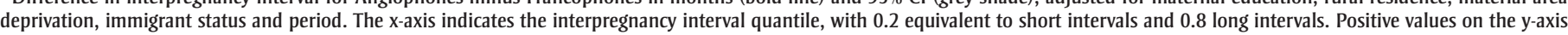
indicate that Anglophones have greater intervals than Francophones, and negative values that Francophones have greater intervals than Anglophones. 


\section{FIGURE 5}

Difference in interpregnancy interval between socioeconomically disadvantaged Anglophones and Francophones by maternal age, 1989-2011, Quebec ${ }^{\mathrm{a}}$
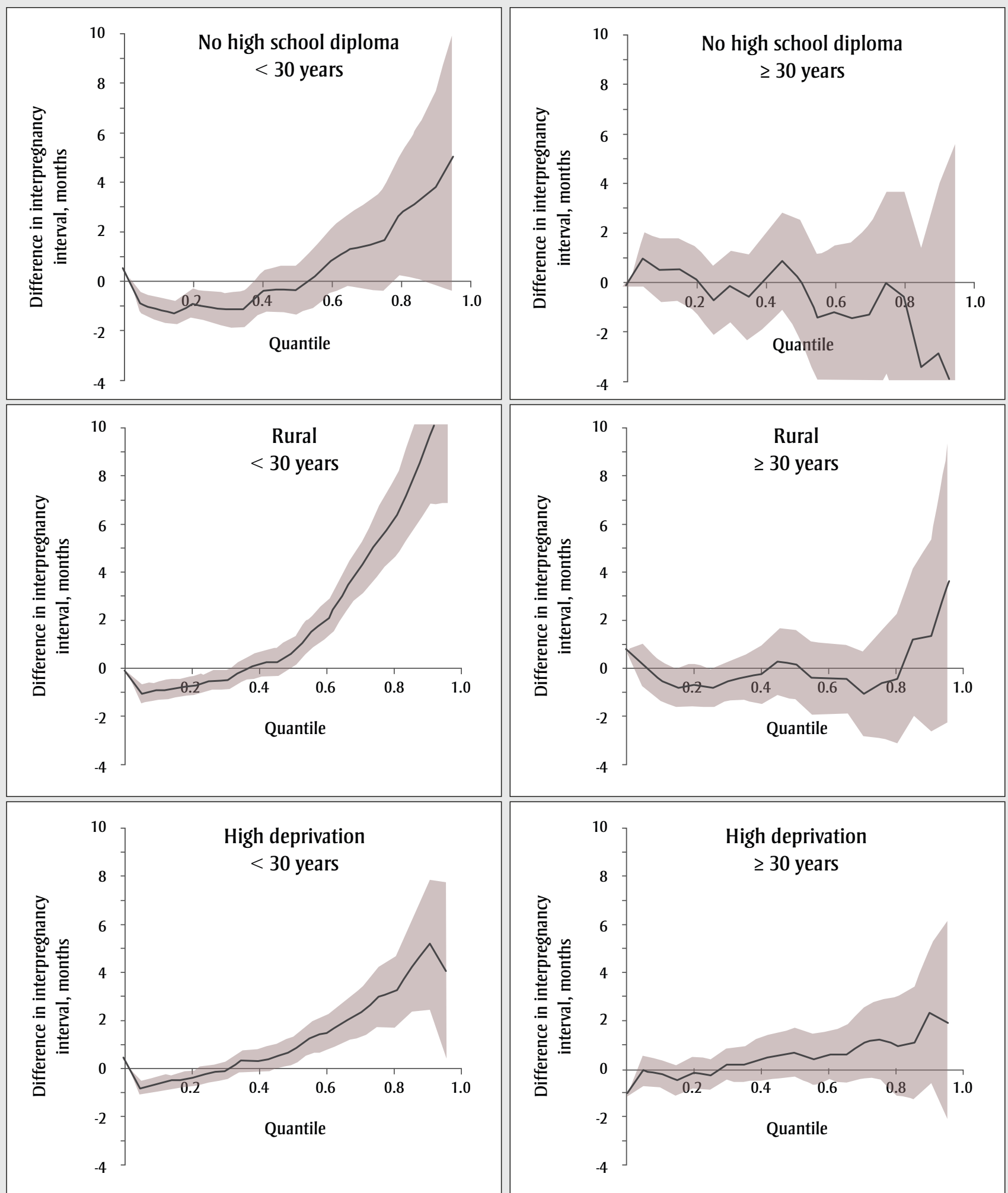

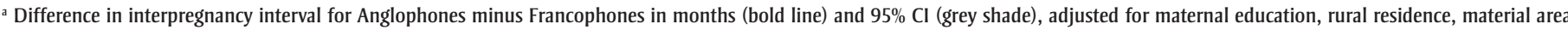

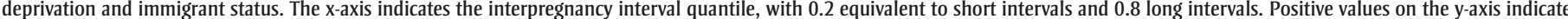

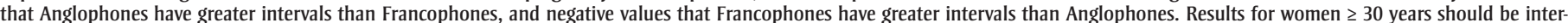
preted with caution as long interpregnancy intervals are rare in this group. 
cultural or socioeconomic groups have not been studied in other countries. In Quebec, there is substantial evidence that disadvantaged Anglophones have increasing rates of stillbirth, preterm birth, and small-for-gestational-age birth. ${ }^{18,19}$ Anglophone fertility is also rising, particularly among materially deprived women. ${ }^{21}$ These trends coincide with rising unemployment and low income among Anglophones. ${ }^{16}$ The structure of language groups may also have changed over time due to disproportionate emigration of advantaged Anglophones to other Canadian provinces, ${ }^{31}$ and an increase and change in type of immigrants in Quebec. We found no evidence however that AnglophoneFrancophone differences in interpregnancy intervals widened during the study.

\section{Strengths and limitations}

We had population-based data for more than 500000 parous women in a large province of Canada, and used quantile regression, a method that estimated differences for both short and long interpregnancy intervals. There are nonetheless study limitations. The clinical impact of a few months difference in interpregnancy intervals is unknown, although effects at the population level may be significant. The results suggest that a change of only 1 month in the interpregnancy intervals of the Anglophone population could have a beneficial impact on maternal-infant health. Information on the delivery date for the first pregnancy was self-reported by the mother, and in some cases, may have been incorrectly recorded. Socioeconomic status and language were only available at the second delivery, and we do not know the extent to which these could have differed compared with the first birth. We could not adjust for maternal age, and cannot rule out residual confounding due to differences in maternal age between linguistic groups. We could not study bilingual or other language groups due to sample size limitations, or account for material deprivation as an area-level variable in a multilevel analysis. This study was limited by measures of socioeconomic status that were imperfect. We did not have information on household income, or any measure of socioeconomic status of the partner, and area deprivation is an ecological marker that may not reflect individual deprivation. We did not have information on abortion, immigration period, family planning, breastfeeding, contraception, or other characteristics potentially related to interpregnancy intervals..$^{5,6,22,23}$ Finally, Quebec is a multicultural population where language does not necessarily reflect ethnicity, hence the results cannot be inferred to ethnic subgroups.

\section{Conclusion}

This study found evidence of differences in interpregnancy intervals between Anglophones and Francophones of Quebec. Disadvantaged minority Anglophones had unfavourable interpregnancy intervals compared with disadvantaged Francophones. These findings suggest that lingocultural differences in interpregnancy intervals may be present in Canada, and add to the growing evidence that socioeconomically disadvantaged Anglophones may be a vulnerable population in Quebec.

\section{Acknowledgements}

This work was supported by Health Canada via the McGill Training and Retention of Health Professionals Project; and a Fonds de recherche du QuébecSanté career award (34695).

\section{Conflicts of interest}

The authors have no conflicts of interest to declare.

\section{Authors' contributions and statement}

NA conceived and designed the study, and LL and MBB performed the statistical analysis with guidance from NA. ADB and AC helped interpret the results. NA, MBB and ADB drafted the manuscript, and LL and AC revised it for critical intellectual content. All authors approved the final version submitted.

The content and views expressed in this article are those of the authors and do not necessarily reflect those of the Government of Canada.

\section{References}

1. Gardosi J, Madurasinghe V, Williams $\mathrm{M}$, et al. Maternal and fetal risk factors for stillbirth: population based study. BMJ. 2013;346:f108. doi: 10.1136 /bmj.f108.
2. Schaaf JM, Liem SM, Mol BW, et al. Ethnic and racial disparities in the risk of preterm birth: a systematic review and meta-analysis. Am J Perinatol. 2013;30(6):433-50. doi: $10.1055 / \mathrm{s}-0032-1326988$.

3. Zipursky AR, Park AL, Urquia ML, et al. Influence of paternal and maternal ethnicity and ethnic enclaves on newborn weight. J Epidemiol Community Health. 2014;68(10):942-9. doi: 10.1136 /jech-2014-204257.

4. Nabukera SK, Wingate MS, Salihu HM, et al. Pregnancy spacing among women delaying initiation of childbearing. Arch Gynecol Obstet. 2009; 279(5):677-84. doi: 10.1007/s00404 $-008-0793-2$.

5. Gemmill A, Lindberg LD. Short interpregnancy intervals in the United States. Obstet Gynecol. 2013;122(1): 64-71. doi: 10.1097/AOG.0b013e3182 $955 \mathrm{e} 58$.

6. Cheslack-Postava K, Winter AS. Short and long interpregnancy intervals: correlates and variations by pregnancy timing among U.S. women. Perspect Sex Reprod Health. 2015; 47(1):19-26. doi: 10.1363/47e2615.

7. Copen CE, Thoma ME, Kirmeyer S. Interpregnancy intervals in the United States: data from the Birth Certificate and the National Survey of Family Growth. Natl Vital Stat Rep. 2015; 64(3):1-10.

8. Conde-Agudelo A, Belizán JM. Maternal morbidity and mortality associated with interpregnancy interval: cross sectional study. BMJ. 2000; 321(7271):1255-9.

9. World Health Organization. Report of a WHO technical consultation on birth spacing. Geneva, Switzerland: World Health Organization, Department of Reproductive Health and Research; 2007:p. 48. Available from: http://www.who.int/reproductivehealth /publications/family_planning/WHO_ RHR_07_1/en/

10. Sahin Ersoy G, Giray B, Subas S, et al. Interpregnancy interval as a risk factor for postmenopausal osteoporosis. Maturitas. 2015;82(2):236-40. doi: 10.1016/j.maturitas.2015.07.014. 
11. Ngo AD, Roberts CL, Figtree G. Association between interpregnancy interval and future risk of maternal cardiovascular disease-a populationbased record linkage study. BJOG. 2016;123(8):1311-8. doi: 10.1111/1471 $-0528.13729$.

12. Gunnes N, Surén P, Bresnahan M, et al. Interpregnancy interval and risk of autistic disorder. Epidemiology. 2013; 24(6):906-12. doi: 10.1097/01.ede .0000434435 .52506 .15 .

13. Ekin A, Gezer C, Taner CE, et al. Impact of interpregnancy interval on the subsequent risk of adverse perinatal outcomes. J Obstet Gynaecol Res. 2015;41(11):1744-51. doi: 10.1111 /jog.12783.

14. Zhu B-P, Rolfs RT, Nangle BE, et al. Effect of the interval between pregnancies on perinatal outcomes. N Engl J Med. 1999;340(8):589-94.

15. Statistics Canada. English, French and official language minorities in Canada. [Internet]. Ottawa (ON): Statistics Canada; 2017 [Statistics Canada Catalogue No.: 98-200-X201 6011]. Available from: http://www 12 .statcan.gc.ca/census-recensement /2016/as-sa/98-200-x/2016011/98-200 -x2016011-eng.cfm

16. Corbeil J-P, Chavez B, Pereira D. Portrait of official-language minorities in Canada - anglophones in Quebec. Ottawa (ON): Statistics Canada; 2010 [Statistics Canada Catalogue No.: 89-642-X]. Available from: http:// www.deslibris.ca/ID/228980

17. Lussier $\mathrm{M}-\mathrm{H}$, Trempe N. The socioeconomic status of anglophones in Québec report. Montréal (QC): Viceprésidence aux affaires scientifiques, Institut national de santé publique du Québec; 2012. Available from: http:// collections.banq.qc.ca/ark:/52327 /2221331

18. Auger N, Park AL, Harper S. Francophone and Anglophone perinatal health: temporal and regional inequalities in a Canadian setting, 1981-2008. Int J Public Health. 2012; 57(6):925-34. doi: 10.1007/s00038-012 $-0372-y$.

19. Auger N, Daniel M, Mortensen L, et al. Stillbirth in an Anglophone minority of Canada. Int J Public Health. 2015;60(3):353-62. doi: 10.1007/s00038 -015-0650-6.
20. Institut de la statistique du Québec. Le bilan démographique du Québec. Édition 2017 [Internet]. Institut de la statistique du Québec; 2017. Available from: www.stat.gouv.qc.ca/statistiques /population-demographie/bilan2017 .pdf

21. Auger N, Bilodeau-Bertrand M, Costopoulos A. Identifying emerging reproductive vulnerability: an approach to decompose differences in total fertility. Ann Epidemiol. 2017;27(2):8995.e1. doi: 10.1016/j.annepidem.2016 .10 .007

22. Isquick $\mathrm{S}$, Chang $\mathrm{R}$, Thiel de Bocanegra $\mathrm{H}$, et al. Postpartum contraception and interpregnancy intervals among adolescent mothers accessing public services in California. Matern Child Health J. 2016;21(4):752-9. doi: 10.1007/s10995-016-2164-0.

23. Kaharuza FM, Sabroe S, Basso O. Choice and chance: determinants of short interpregnancy intervals in Denmark. Acta Obstet Gynecol Scand. 2001;80(6):532-8.

24. Pampalon R, Hamel D, Gamache P, et al. An area-based material and social deprivation index for public health in Québec and Canada. Can J Public Health. 2012;103(8 Suppl 2):S17-22.

25. Luo ZC, Wilkins R. Degree of rural isolation and birth outcomes. Paediatr Perinat Epidemiol. 2008;22(4):341-9. doi: 10.1111/j.1365-3016.2008.00938.x.

26. Schisterman EF, Cole SR, Platt RW. Overadjustment bias and unnecessary adjustment in epidemiologic studies. Epidemiology. 2009;20(4):488-95. doi: 10.1097/EDE.0b013e3181a819a1.

27. Etienne J-M, Narcy M. Gender wage differentials in the French nonprofit and for-profit sectors: evidence from quantile regression. Ann Econ Stat. 2010;(99):67-90.

28. Martins PS, Pereira PT. Does education reduce wage inequality? Quantile regression evidence from 16 countries. Labour Econ. 2004;11(3):355-71.

29. Heck KE, Braveman P, Cubbin C, et al. Socioeconomic status and breastfeeding initiation among California mothers. Public Health Rep. 2006; 121(1):51-9.
30. Bentolila Y, Ratzon R, Shoham-Vardi I, et al. Effect of interpregnancy interval on outcomes of pregnancy after recurrent pregnancy loss. J Matern Fetal Neonatal Med. 2013;26(14): 1459-64. doi: 10.3109/14767058.2013 .784264

31. Floch W, Pocock J. Emerging trends in the socio-economic status of English-speaking Quebec: those who left and those who stayed. In: The Vitality of ESC: From Community Decline to Revival. CEETUM, Université de Montréal, Montréal (QC): R.Y. Bourhis; 2008. p. 35-62. 